\title{
IN SILICO BINDING INTERACTION STUDY OF MEFENAMIC ACID AND PIROXICAM ON HUMAN ALBUMIN
}

\author{
JOSHITA DJAJADISASTRA, HAMKA DECKY PURNAMA, ARRY YANUAR* \\ Department of Pharmacy, Faculty of Pharmacy, Universitas Indonesia, Depok, Indonesia. Email: arry.yanuar@farmasi.ui.ac.id
}

Received: 21 April 2017, Revised and Accepted: 18 August 2017

ABSTRACT

Objective: A drug can replace other drugs in the same binding position in protein plasma, increasing pharmacological response due to the increased free drug concentration. Drug shifting is critical when a compound is tightly bound to a protein. For example, a binding fraction change, from $98 \%$ to $94 \%$, may increase the free fraction 3 times, from $2 \%$ to $6 \%$. Knowing that there is an interaction between mefenamic acid and piroxicam on plasma protein, more specifically on human albumin, this study aimed to visualize the interaction between both drugs and human albumin in silico.

Methods: This study used AutoDock4 as a molecular docking technique, obtaining binding visualizations, binding energies $(\Delta \mathrm{G})$, and inhibition constants $\left(\mathrm{K}_{\mathrm{i}}\right)$ of both mefenamic acid-albumin and piroxicam-albumin bindings.

Results: It is shown that the $\Delta \mathrm{G}$ and $\mathrm{K}_{\mathrm{i}}$ of both mefenamic acid and piroxicam are $-5.47 \mathrm{kcal} / \mathrm{mol}(98.59 \mu \mathrm{M})$ and $-7.46 \mathrm{kcal} / \mathrm{mol}(3.42 \mu \mathrm{M})$, respectively.

Conclusions: The process of binding mefenamic acid to albumin can be substituted with piroxicam due to its higher $\Delta \mathrm{G}$ and $\mathrm{K}_{\mathrm{i}}$ values. It can be predicted that this interaction will increase the free mefenamic acid concentration in blood plasma which, in turn, enhances the therapeutic effect.

Keywords: Albumin, Mefenamic acid, Piroxicam, Molecular docking.

(c) 2017 The Authors. Published by Innovare Academic Sciences Pvt Ltd. This is an open access article under the CC BY license (http://creativecommons. org/licenses/by/4. 0/) DOI: http://dx.doi.org/10.22159/ijap.2017.v9s1.56_62

\section{INTRODUCTION}

The pharmacological activity of a drug depends on its concentration in the receptor, which is directly related to the free drug concentration in plasma. Changes in the free drug concentration in plasma, due to a result of drug interactions, can be detected in vitro by a variety of protein binding determination methods. In various clinical conditions, measurements of total drug concentrations do not provide necessary information about the fraction of the free drug in plasma that is available for distribution, elimination, and pharmacodynamics action. Thus, accurate measurement of the concentration of free drug in the plasma is very important in clinical supervision. Free drug concentration in plasma is affected by changes in drug-protein binding. A drug's plasma protein binding is critical to its clinical pharmacokinetics and pharmacodynamics, which are described by drug-protein binding parameters including the number of types of binding sites, the number of binding sites, and the affinity or strength of drug-protein binding [1].

A drug can shift other drugs from its binding to plasma proteins, causing a sudden increase of pharmacologic response due to an increase in the concentration of the free drug. Drug shifting is very important when the compound is strongly bound to the protein. A change in binding from $98 \%$ to $94 \%$ may increase the fraction of the free drug by 3 times, from $2 \%$ to $6 \%$. As for the drug that weakly bounded to plasma proteins, it will experience a decrease in its protein binding and cause an insignificant clinical increase of its pharmacological activity [1]. A previous study provides proof that interactions between two drugs in plasma proteins binding are very important. Many methods are available to determine the amount of drug bound to plasma proteins, however, in the clinical evaluation of drug therapy, equilibrium dialysis, and ultrafiltration are the most commonly used methods. These methods are proven to be reliable in providing data on protein binding [1].

The drugs used in this study were mefenamic acid and piroxicam. Piroxicam is a nonsteroidal anti-inflammatory (NSAIDs) drug, while mefenamic acid is an analgesic drug that is widely used in the Indonesian community. Both are weak acids, thus they have a greater affinity for binding to albumin. The use of both analgesic and NSAIDs simultaneously, as pain killers for rheumatic disease, allows for an interaction between the two drugs in the plasma, which is associated to their binding to albumin. Studies on the interaction between the two drugs are useful for the development of both the drugs and may serve as useful information for health-care practitioners about their safety for patients [1]. Our previous in vitro study by Djajadisastra suggested an interaction that occurred between mefenamic acid and piroxicam in binding to albumin when given simultaneously. The percentage of albumin bound to mefenamic acid was $98.53 \%$ with a constant association of $1.24 \times 10^{5} \mathrm{l} / \mathrm{mol}$, while the percentage of piroxicam bound to albumin was $95.06 \%$ with a constant association of $4.36 \times 10^{4} \mathrm{l} / \mathrm{mol}$. When mefenamic acid and piroxicam were administered simultaneously, the percentage of piroxicam bound to albumin increased from $95.06 \%$ to $96.71 \%$, while mefenamic acid decreased from $98.53 \%$ to $95.39 \%$. However, the mechanism of the interaction cannot be explained [1]. Thus, in the current in silico study, we investigated the interaction between mefenamic acid and piroxicam in binding to albumin. In silico experiments with a molecular docking method were performed with AutoDock4 software to determine parameters that play important roles in the binding of mefenamic acid and piroxicam to human albumin.

\section{METHODS}

\section{Instrument and software}

Computer with specs of at least one gigabyte of RAM memory and PyMOL, Vega ZZ, Collaborative Computational Project 4 (CCP4), Cygwin, and AutoDock software installed were used. The structures used were:

1. A three-dimensional structure of human albumin was downloaded from the PDB with PDB identities 1A06, 1BM0, and 1E78.

2. A three-dimensional structure of mefenamic acid was downloaded from PubChem.

3. A three-dimensional structure of piroxicam was downloaded from PubChem.

Separation of chain crystal structures in 1A06, 1BM0, and 1E78 Crystal structure albumin consists of two chains, namely, A and B. For the docking process; we used one of the chains. When separating the 
albumin chains in the crystal structure, PyMOL software was used to obtain a crystal structure of the $1 \mathrm{AO} 6$ chain $\mathrm{A}$ and $\mathrm{B}, 1 \mathrm{BM} 0$ chain $\mathrm{A}$ and $\mathrm{B}$, as well as the $1 \mathrm{E} 78$ chain $\mathrm{A}$ and $\mathrm{B}$.

\section{Superposing crystal structure 1A06, 1BM0, and 1E78}

Based on a virtual screening study, the crystal structure of 1 E78 chain A was used. The reason to use this crystal structure is because the preliminary studies had been done and showed that 1E78 chain A had highest binding affinity score. This chain was later superposed with the crystal structures of $1 \mathrm{E} 78$ chain $\mathrm{B}, 1 \mathrm{AO} 6$ chain $\mathrm{A}$ and $\mathrm{B}$, and $1 \mathrm{BM} 0$ chain $\mathrm{A}$ and $\mathrm{B}$, using CCP4 software that generates a file with the extension_lsq.pdb.

\section{Depreciation of energy (energy minimization) and determination} of the best conformation of ligand structure

The energy of mefenamic acid and piroxicam ligands used for molecular docking were minimized using the Vega ZZ software that accepts input, in the form of ligands, in any files. In this step, a hydrogen atom was added to each ligand structure, which was then calculated for their potentiality using the SP4 force field and Gasteiger charge calculation. The release of energy was performed using the Minimization Step Trust 1000 program and Toler 0.01 . Determination of the best conformation was performed using a conformational search. The result was stored in the. pdb file.

\section{Development of ligand and macromolecule files}

The best ligand conformation result from Vega ZZ was input into AutoDockTools to create a.pdbqt output file. Hydrogen was added to the polar macromolecules. The charges were calculated by computing Gasteiger charges, and the process was continued with the addition of nonpolar hydrogen.

\section{Development of grid parameter file}

A grid parameter in an AutoGrid4 module was used to describe the region of the receptor and ligand type for calculating its potentiality. A ligand consists of an electrostatic map; a desolvation map; and specific, separate atoms. Since ligand type is dependent on atom type, map choice was based on the type of ligand preferred. After the type of ligand was selected, the size of the grid box was determined. The grid box defines the magnitude of the molecular docking area. Determination of the grid box was based on the dimensions of the 1E78 chain A. The grid box must be able to accommodate a molecule as it rotates freely, generally, twice the distance of the farthest atom and the ligand binding site covers an area of macromolecules.

\section{Table 1: AutoGrid4 command on cygwin}

1.autogrid4 -p 1E78_chainA.gpf -l 1E78_chainA.glg \&

input: $1 \mathrm{E} 78$ chainA.gpf

output: 1E78_chainA.maps.fld, 1E78_chainA.maps.xyz, 1E78_chainA. glg,

1E78_chainA.A.map, 1E78_chainAN.map, 1E78_chainA.HD.map,

1E78_chainA.0A.map, 1E78_chainA.d.map, 1E78_chainA.e.map

2. autodock4 -p 1E78_chainA.dpf -l 1E78_chainA.dlg \&

input: 1E78_chainA.dpf

output : 1E78_chainA.dlg
The docking technique used was blind docking, a technique in which the ligand docking is oriented to the entire surface of the macromolecules target, in this case, albumin. Based on the dimensions of albumin, the $160 \times 160 \times 60$ grid points box size was used, with a point measuring $0.500 \AA$ [2]. The development of grid parameters was done using the AutoDockTools grid program which utilizes ligand and macromolecule input from a.pdbqt file, resulting in a. gpf file output. This gpf file was then used as an input file to obtain a grid map with the AutoGrid4 command on Cygwin (Table 1).

\section{Determination of docking parameters}

Determination of docking parameters was performed using AutoDockTools, which utilizes ligands and macromolecule inputs in a. pdbqt file to produce a. dpf output file (docking parameter file). The parameters used to determine docking parameters are the default parameters contained in the docking program. The algorithm used was the Lamarckian genetic algorithm (LGA) with 100 GA runs and the maximum number of energy evaluations ( 25 million). This dpf file was then used as an input to get the docking results using the AutoDock4 command on Cygwin (Table 1). Each ligand-macromolecule combination was performed repeatedly.

\section{Analysis of docking results}

The docking analysis was in a. dlg file that records details about the input file, the number of runs in the docking, the docking structure found at the end of each run, free energy $(\Delta G)$ of each conformation tethering, and inhibition constant values. At the end of the dlg file, there is a summary of the docking (Figs. 1 and 2). Docking results were arranged in groups called clusters. Each run, which has similarities in terms of the value of the free energy and conformation to active sites, are contained in a single cluster (Fig. 1 and 2). These clusters indicate the spread of data from 100 conformations docking results, thus called the best cluster and best dock (Table 2). Convergent results were generated when there was only the best cluster available (Fig. 2). Meanwhile, divergent results were generated when the best dock and best cluster were available in separate clusters (Fig. 1).

When each experiment only resulted in convergent results, the one with the lowest free energy was chosen. In the case that divergent data were obtained, the experiment with the smallest cluster best dock and cluster best cluster free energy was chosen. The experiment with posing (conformation), scoring (free energy value), and the best percentage was further analyzed. An experiment, visually chosen, was analyzed at its active site using a molecular visualization program PyMOL. Hydrogen bonding between ligands with macromolecules was also analyzed manually with PyMOL software.

\section{RESULTS}

\section{Separation of crystal structure}

The crystal structure of $1 \mathrm{A06}, 1 \mathrm{BM} 0$, and $1 \mathrm{E} 78$ has two subunits, A and B. The process of "Program, Edit, File, GDP" in the CCP4 program separated the subunits in each crystal, resulting in crystal structures $1 \mathrm{AO} 6$ chain $\mathrm{A}$ and $\mathrm{B}, 1 \mathrm{BM} 0$ chain $\mathrm{A}$ and $\mathrm{B}$, and $1 \mathrm{E} 78$ chain $\mathrm{A}$ and B. Crystal structure 1E78 chain A was used as a macromolecule target based on the structural similarity of the three existing albumin structures.

Table 2: Result of molecular docking

\begin{tabular}{llllll}
\hline Ligand & Trial & Posing category & $\boldsymbol{\Delta G}(\mathbf{k k a l} / \mathbf{m o l})$ & Percentage & Ki $(\boldsymbol{\mu} \mathbf{M})$ \\
\hline Mefenamic acid & Trial I & Best dock & -6.13 & 4 & 32.27 \\
& & Best cluster & -5.43 & 45 & 104.05 \\
& Trial II & Best dock & -6.36 & 7.47 & 21.65 \\
Piroxicam & & Best cluster & -7.82 & 35 & 1.84 \\
& Trial I & Best dock & -7.82 & 84 & 1.84 \\
& & Best cluster & -7.46 & 51 & 3.42 \\
& Perc II & Best dock & -7.46 & 51 & 3.42 \\
\hline
\end{tabular}




\begin{tabular}{|c|c|c|c|c|c|c|c|}
\hline \multirow{4}{*}{ 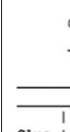 } & \multirow{2}{*}{\multicolumn{4}{|c|}{ CLUSTERING HISTOGRAM }} & \multicolumn{3}{|l|}{ ENDMDE } \\
\hline & & & & & MODEL & & \\
\hline & & & & & USER & Number of conformations in this $\mathrm{cl}$ & ster $=35$ \\
\hline & Lowest & | Run | & Mean & Num | Histogram & USER & & \\
\hline -ter I 1 & Iinding & 1 & Binding & in । & USER & RMSD from reference structure & $=7.047 \mathrm{~A}$ \\
\hline Rank I & & & & $\begin{array}{llllll}\mid \text { Clus } & 5 & 10 & 15 & 20 & 25\end{array}$ & USER & & \\
\hline 30 & & & & & USER & Estimated Free Energy of Binding & $=-5.47 \mathrm{kcal} / \mathrm{mol} \quad[=(1)+$ \\
\hline EI & & & & - - - - & $(2)+13$ & $-(4)]$ & \\
\hline $1 T$ & -6.36 & $|100|$ & -6.07 & 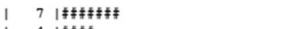 & USER & Estimated Inhibition Constant, $\mathrm{Ki}$ & $=98.59$ uM (micromolar) \\
\hline 21 & -6.33 & i 381 & -6.26 & 4 | $\neq \neq \neq \neq$ & [Terpe & cature $=298.15 \mathrm{~K}]$ & \\
\hline 31 & -5.62 & i 39 i & -5.62 & 1 if & USER & & \\
\hline 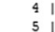 & $\begin{array}{l}-5.51 \\
-5.47\end{array}$ & 551 & $\begin{array}{l}-5.31 \\
-5.28\end{array}$ & 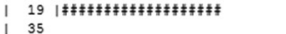 & USER & (1) Final Intermolecular Energy & $=-6.38 \mathrm{kcal} / \mathrm{mol}$ \\
\hline 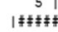 & 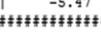 & $\begin{array}{c}11 \\
\neq \neq \neq \neq \neq \neq \neq \\
12\end{array}$ & 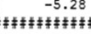 & & USER & $\mathrm{vdW}+$ Hbond + desolv Energy & $=-5.97 \mathrm{kcal} / \mathrm{mol}$ \\
\hline & & $124 \mid$ & & 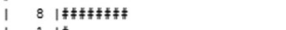 & USER & Electrostatic Energy & $=-0.41 \mathrm{kcal} / \mathrm{mol}$ \\
\hline 71 & -4.96 & 45 & -4.96 & 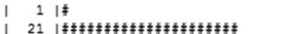 & USER & (2) Final Total Internal Energy & $=-0.16 \mathrm{kcal} / \mathrm{mol}$ \\
\hline $\begin{array}{ll}8 \\
91\end{array}$ & $\begin{array}{l}-4.82 \\
-4.28\end{array}$ & $\begin{array}{l}1 \\
1 \\
1\end{array} 651$ & $\begin{array}{l}-4.73 \\
-4.24\end{array}$ & 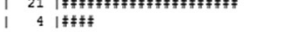 & USER & (3) Torsional Free Energy & $=+0.82 \mathrm{kcal} / \mathrm{mol}$ \\
\hline & & & & & USER & (4) Unbound System's Energy & $=-0.25 \mathrm{kcal} / \mathrm{mol}$ \\
\hline
\end{tabular}

Fig. 1: (a and b) Result of albumin-mefenamic acid complexes

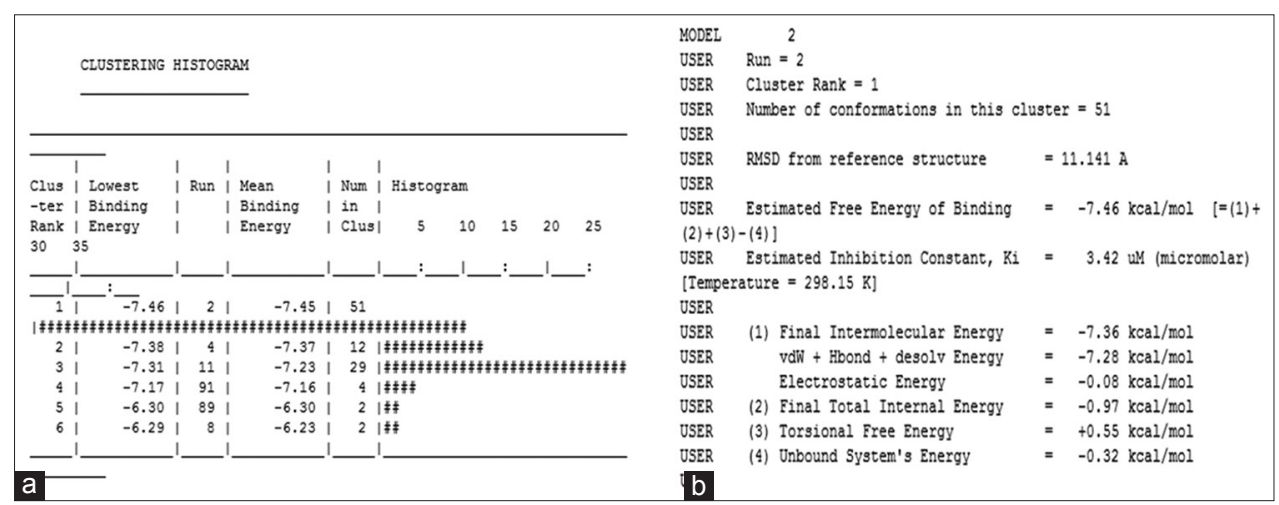

Fig. 2: (a and b) Result of albumin-piroxicam complexes

\section{Superposing crystal structure 1A06, 1BM0, and 1E78}

Results of superposing the collection of CCP4 programs from the 1E78 $A$ and $B$ chains showed a root-mean-square deviation (RMSD) value of $0.566 \AA$ (Table 3 ). This value explains that there is no significant difference in the two structures (RMSD $<2 \AA$ ).

Decrease of energy (energy minimization) and determination of best conformation of ligand structure

Vega ZZ software produced the best conformation of mefenamic acid and piroxicam with the lowest energy. The lowest energy showed the spontaneous binding between mefenamic acid and piroxicam with the receptors. The best conformation with the lowest energy is very important in the process to obtain the best molecular docking results.

\section{Development of ligand and macromolecule files}

AutoDockTools produced ligands and macromolecules in. pdbqt files, making them ready to be used as input for the docking process. This was due to the AutoDock docking process only accepting. pdbqt files as input $[3,4]$.

\section{Development of grid parameter file}

Each ligand has a map E (electrostatic) and map D (desolvation). All files have the extension.map. In addition, AutoGrid4 also generates files with the extensions. glg., maps. fld, and. maps. xyz. The result of grid optimization was a grid map of specific atoms on the ligand type, with amounts depending on the type of atoms present in the ligand, as well as the electrostatic and desolvation map [5].

\section{Development of docking parameter file}

A docking parameter file was generated with AutoDockTools and has a file extension. dpf. This file contains parameters used in docking.

\section{Analysis of docking results}

The results of molecular docking were included in the. dlg file. Docking of mefenamic acid to the 1E78 chain A gave divergent results (Fig. 2).
Table 3: Summary of 3D superposed structure of albumin

\begin{tabular}{lll}
\hline Moving & Fix & RMSD $(\AA)$ \\
\hline 1A06 & 1E78 & 0.839 \\
1E78 & 1BM0 & 0.858 \\
1BM0 & 1A06 & 0.241 \\
1A06 chain A & 1A06 chain B & 0.357 \\
1BM0 chain A & 1BM0 chain B & 0.278 \\
1E78 chain A & 1E78 chain B & 0.566 \\
\hline
\end{tabular}

The posing of mefenamic acid has smallest free energy clusters, best cluster, and cluster best dock located in different clusters (Fig. 1). Piroxicam has relatively convergent results on the $1 \mathrm{E} 78$ chain $\mathrm{A}$, where the posing of piroxicam with the smallest free energy clusters, best clusters, and cluster best dock was in one cluster (Fig. 2).

\section{DISCUSSION}

Albumin has been known to be a primary drug transport and has become the subject of binding studies and drug interactions. One of the expected drug interactions that occur in albumin is mefenamic acid and piroxicam competing to bind to albumin, leading to an increased therapeutic dose concentration of mefenamic acid in the blood [1]. In silico molecular tethering is used as a method to analyze the interaction between mefenamic acid and piroxicam when they are molecularly bound to albumin, confirming the interactions that occur between the two drugs.

Current molecular docking in AutoDockTools primarily uses default parameters. Exceptions to this are the number of conformation results from a single molecular docking (100) and the amount of energy used to run the docking process evaluated using a LGA docking algorithm $[3,4]$. Each conformation generated was grouped into clusters based on the value of the RMSD, with a maximum tolerance RMSD value of each member in the cluster being $2 \AA$. The results of the docking were then 
selected based on the criteria of energy and geometry match quality. The ligand structure that was used for docking analysis was optimized using the SP4 force field in the Vega ZZ software.

The 3D structures used in this study were the crystal structures of human serum albumin (PDB ID: 1E78, 1A06, and 1BM0) downloaded from the Protein Data Bank (PDB) website [2,6-8]. Of the three structures, 1 E78 had a larger X-ray crystallization resolution $(2.60 \AA)$ than the other two crystal structures. $1 \mathrm{BM} 0$ and $1 \mathrm{AO} 6$ crystal had the same R value, $2.50 \AA$ A. Macromolecular targets affect the quality of posing and scoring of molecular docking thus, the selection and preparation of the structure model for the macromolecule target is an important variable [5].

The results of superposing 1E78, 1BM0, and $1 \mathrm{AO} 6$ provide threedimensional structural similarity (RMSD values of $<2 \AA$ ), where superposing $1 \mathrm{E} 78$ and $1 \mathrm{A0} 6$ had a RMSD value of $0.839 \AA$, $1 \mathrm{E} 78$ and $1 \mathrm{BM} 0$ had a RMSD value $0.858 \AA$, and $1 \mathrm{AO} 6$ and $1 \mathrm{E} 78$ had a RMSD value of $0.241 \AA$ (Table 3). Due to albumin consisting of two subunits, each of them was superposed, resulting in three-dimensional structural similarity, with RMSD values of $0.357 \AA, 0.278 \AA$, and $0.566 \AA$ for $1 \mathrm{A0} 06$, $1 \mathrm{BM} 0$, and 1E78, respectively (Table 3 )

Mefenamic acid is a compound with three active torques, as detected by AutoDockTools, while piroxicam has two active torsion. The number of bonds that can rotate on a ligand determines the flexibility of the ligand [5]. Ligands' flexibility may have greater effects on proper conformation predictions compared to the polarity and size of the ligand. Ligand flexibility is affected by posing and docking results. These torsion and ligand flexibility cause difficulty distinguishing conformational results, especially between posing with smaller free energy $(\Delta G)$ and a good conformation with larger free energy at the divergent docking results (Fig. 1).

The grid parameter file was prepared using AutoDockTools, obtaining a. gpf file as the output, which was then analyzed using the AutoGrid4 command in the Cygwin program (Table 1). From this process, files with extensions of. glg., maps. fld, and. maps.xyz were obtained. Docking parameter files were prepared using the AutoDockTools program, obtaining a. dpf file as the output, a file that contains parameters for docking. The file was then applied to the Cygwin program with the AutoDock4 command (Table 1). The result of this process is a file with the extension .dlg, which stores all docking results data. From the.dlg file, the spread of cluster, $\Delta \mathrm{G}$, and $\mathrm{K}_{\mathrm{i}}$ that are used for docking result analysis can be seen (Figs. 1 and 2 and Tables 2 and 4).

The best conformation of mefenamic acid, with $\Delta \mathrm{G}$ values and $\mathrm{K}$ in the $1 \mathrm{E} 78$ chain A structure was $-5.47 \mathrm{kcal} / \mathrm{mol}$ and $98.59 \mathrm{~lm}$, while those of piroxicam were $-7.46 \mathrm{kcal} / \mathrm{mol}$ and $3.42 \mathrm{~lm}$ (Table 4 ). $\Delta \mathrm{G}$ values describe the interaction between ligands and macromolecules. The smaller the value of $\Delta \mathrm{G}$, the smaller the energy required to occupy the ligand binding site, causing smaller interactions. Thus, the ligand is relatively more comfortable in the macromolecular targets. Meanwhile, the value of $K_{i}$ describes the inhibition constant of ligand to bind a macromolecule. The smaller the value of $\mathrm{K}_{i}$, the smaller obstacles that occur when a ligand binds to macromolecules will be. These parameters can influence the strength of bonds between the ligand and macromolecules, thus they can be indicators of the presence of an interaction between ligands in the same macromolecule.

The docking results showed that mefenamic acid bound to domain II, which is binding site I. Mefenamic acid bound to arginine amino acid at sequence $218\left(\mathrm{R}_{218}\right)$ (Figs. 3 and 4) with $1.83 \AA$ (Table 5). Piroxicam bound to the domain I, which is not a binding site I or II. Piroxicam bound to arginine amino acid at sequence $145\left(\mathrm{R}_{145}\right)$ (Figs. 5 and 6) with $1.91 \AA$ (Table 5). The binding that occurred was a hydrogen bond, with RMSD of $<4 \AA$ [6]. This suggests that mefenamic acid and piroxicam do not occupy the same region when binding to albumin, thus the interaction between mefenamic acid and piroxicam is not a competition for the same active site. The difference between the piroxicam and mefenamic
Table 4: Summary of free energy $(\Delta G)$ and inhibition constants $\left(\mathrm{K}_{\mathrm{i}}\right)$ of selected molecular docking

\begin{tabular}{|c|c|c|c|c|}
\hline \multirow[t]{2}{*}{ Macromolecule } & \multicolumn{2}{|c|}{$\Delta \mathrm{G}(\mathrm{kcal} / \mathrm{mol})$} & \multicolumn{2}{|l|}{$\mathrm{Ki}(\mu \mathrm{M})$} \\
\hline & $\begin{array}{l}\text { Mefenamic } \\
\text { acid }\end{array}$ & Piroxicam & $\begin{array}{l}\text { Mefenamic } \\
\text { acid }\end{array}$ & Piroxicam \\
\hline 1E78_chainA & -5.47 & -7.46 & 98.59 & 3.42 \\
\hline
\end{tabular}

Table 5: Distance of ligand binding with macromolecules

\begin{tabular}{lll}
\hline Ligand & Amino acid & Bond distances (̊) \\
\hline Mefenamic acid & Arginine 218 & $1.81 \& 2.03$ \\
Piroxicam & Arginine 145 & 2.18 \\
Mefenamic acid & Lysine 195 & 4.84 \\
Piroxicam & Lysine 195 & 5.64 \\
\hline
\end{tabular}

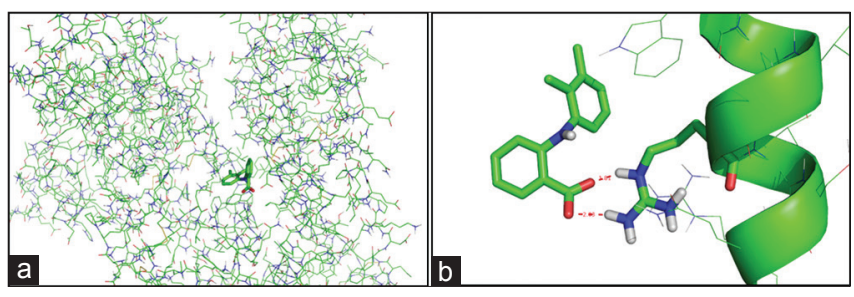

Fig. 3: Binding results from the docking of mefenamic acid on the crystal structure of $1 \mathrm{E} 78$ chain A $1100 \mathrm{GA}$ runs and maximum number of energy evaluations [25 Million])

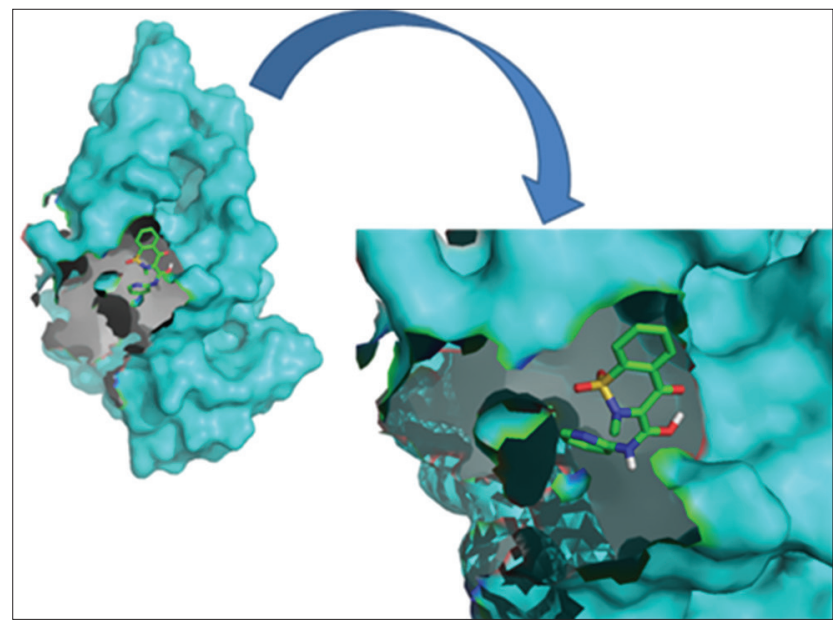

Fig. 4: The docking results of piroxicam to crystal structure 1 E78 chain A (100 GA runs and maximum number of energy evaluations [25 Million])

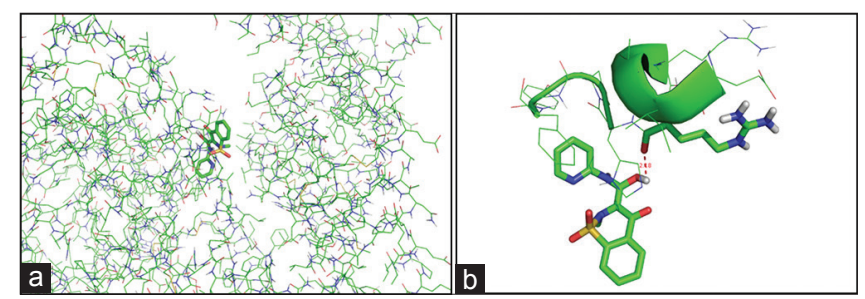

Fig. 5(a and b): Binding results from the docking of piroxicam on the crystal structure 1E78 chain A (100 GA runs and maximum number of energy evaluations [25 Million])

acid binding sites is due to significant structural differences, shown by the sulfone group $\left(\mathrm{SO}_{2}\right)$ in piroxicam (Fig. 7). 

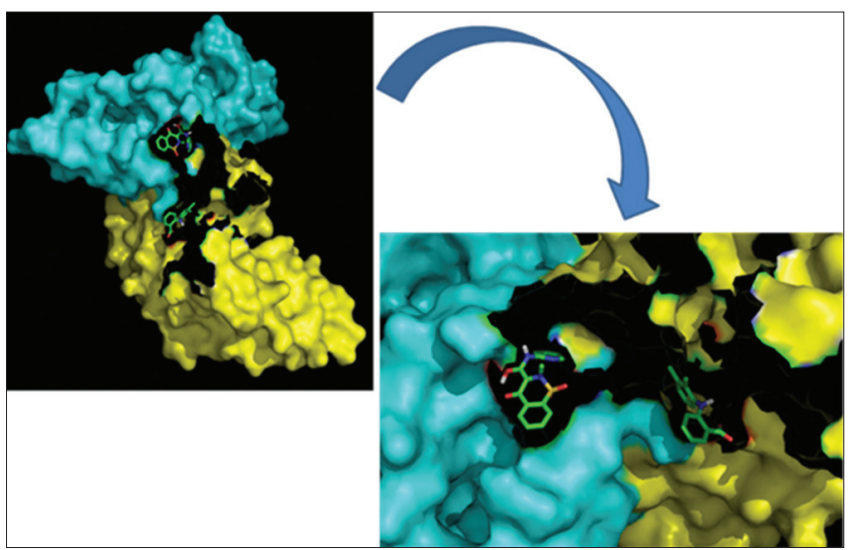

Fig. 6: The docking results of mefenamic acid to crystal structure $1 E 78$ chain A (100 GA runs and maximum number of energy evaluations [25 Million])

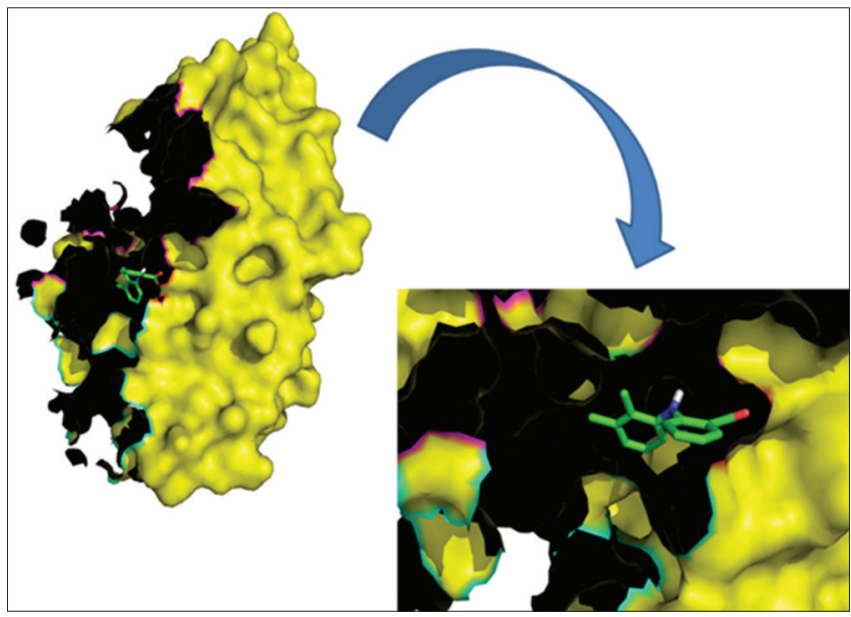

Fig. 7: Superposition result of mefenamic acid-albumin complexes with piroxicam-albumin

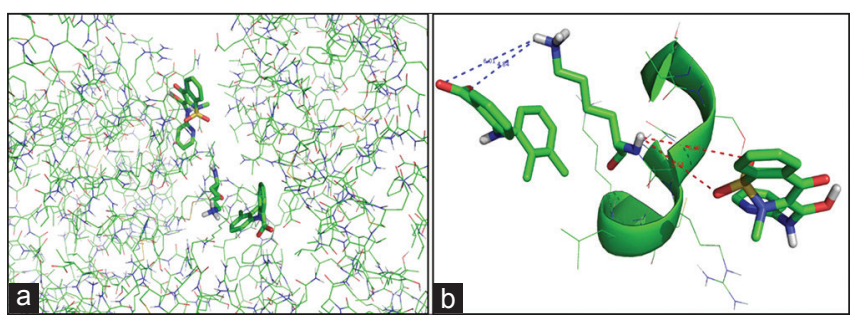

Fig. 8: (a and b) Binding results from superposing mefenamic acid-albumin complexes with piroxicam-albumin

Results of superposing mefenamic acid-albumin and piroxicamalbumin suggest an interaction between mefenamic acid and piroxicam when binding to albumin. This can be seen in the presence of lysine amino acid sequences that bind relatively strong in the second ligand, at sequence $195\left(\mathrm{~K}_{195}\right)$ (Fig. 8). This interaction allows competition between mefenamic acid and piroxicam when binding to albumin, where the bonding of mefenamic acid to albumin was $4.84 \AA$ and piroxicam to albumin was $5.64 \AA$, which means that the distance of mefenamic acid to albumin was shorter than piroxicam to albumin (Table 3).

In vitro studies showed that the amount of mefenamic acid and piroxicam that bound to human plasma albumin was 98.53 and $95.06 \%$, respectively. Mefenamic acid has a constant value of $1.24 \times 10^{5} \mathrm{l} / \mathrm{mol}$ when binding to albumin, whereas piroxicam has a value of $4.36 \times 10^{4} \mathrm{l} / \mathrm{mol}$. A factor that causes more mefenamic acid to bind to albumin than piroxicam is a mefenamic acid having three primary and three secondary binding sites, whereas piroxicam only has one primary and three secondary binding sites. When mefenamic acid and piroxicam are administered simultaneously to bind to albumin, an interaction between the two drugs occurs, shown by the percentage of piroxicam binding to albumin increasing from $95.06 \%$ to $96.71 \%$, while the percentage of a mefenamic acid binding to albumin decreased from $98.53 \%$ to $95.39 \%$. However, the mechanism of the interaction cannot be explained [1]

In in silico molecular docking of mefenamic acid, used to target the macromolecule 1E78 chain A, mefenamic acid's affinity to albumin is weaker than the affinity of piroxicam, as shown by the higher binding energy value of mefenamic acid $(-5.47 \mathrm{kcal} / \mathrm{mol})$ compared to piroxicam $(-7.46 \mathrm{kcal} / \mathrm{mol})$. The inhibition constant value of mefenamic acid to $1 \mathrm{E} 78$ chain $\mathrm{A}(98.59 \mathrm{~lm})$ is much larger than piroxicam $(3.42 \mathrm{~lm})$ (Table 4). This allows the interaction between mefenamic acid and piroxicam when binding to albumin. Like in vitro studies, the mechanism of the interaction also cannot be explained.

Based on the results of molecular docking, piroxicam-albumin has a stronger affinity with albumin compared to mefenamic acid-albumin. In addition, the $\mathrm{K}_{\mathrm{i}}$ value of piroxicam was smaller than that of mefenamic acid. Both parameters suggest the possibility of piroxicam replacing mefenamic acid, preventing it from binding to albumin. These results are consistent with the results of in vitro studies and suggest a possible interaction between mefenamic acid and piroxicam in binding to albumin when administered simultaneously.

\section{CONCLUSION}

Mefenamic acid and piroxicam do not occupy the same site when molecular docking to albumin. Mefenamic acid bound to domain II of albumin and piroxicam bound to domain I. However, there are some interactions that occur between them. The values of $\Delta G$ and $K_{i}$ of piroxicam were smaller than mefenamic acid, allowing piroxicam to replace mefenamic acid in albumin binding when both drugs were administered simultaneously. This can increase the levels of free mefenamic acid in the blood, thus increasing the therapeutic effect of mefenamic acid. This study, however, is not without limitations. Further studies should be performed to investigate the active sites on albumin. Furthermore, the docking process time should be prolonged, considering the spread of some of the results were divergent.

\section{REFERENCES}

1. Djajadisastra $\mathrm{J}$, et al. Determination of parameter values of protein binding of mefenamic acid and piroxicam as the possibility of interaction of both drugs using equilibrium dialysis method. Congress ISFI XIV Bali 2005. p. 16-19.

2. Bourne PE, Addess KJ, Bluhm WF, Chen L, Deshpande N, Feng Z, et al. The distribution and query systems of the RCSB protein data bank. Nucleic Acids Res 2004;32 Database issue: D223-5.

3. Morris GM, Huey R, Lindstrom W, Sanner MF, Belew RK, Goodsell DS, et al. AutoDock4 and AutoDockTools4: Automated docking with selective receptor flexibility. J Comput Chem 2009:30(16):2785-91.

4. Sotriffer CA, Flader W, Winger RH, Rode BM, Liedl KR, Varga JM. Automated docking of ligands to antibodies: Methods and applications. Methods 2000;20(3):280-91.

5. Fitriana W. Penambatan molekuler sitokrom isoform 2c9 dengan fenitoin dan simetidin (Skripsi). Depok: FMIPA UI; 2009. p. 35, 36, 41, 45,450 .

6. Westbrook J, Feng Z, Jain S, Bhat TN, Thanki N, Ravichandran V, et al. The protein data bank: Unifying the archive. Nucleic Acids Res 2002;30(1):245-8

7. Deshpande N, Addess KJ, Bluhm WF, Merino-Ott JC, TownsendMerino W, Zhang Q, et al. The RCSB protein data bank: A redesigned query system and relational database based on the mmCIF schema. Nucleic Acids Res 2005;33 Database issue: D233-7.

8. Bhat TN, Bourne P, Feng Z, Gilliland G, Jain S, Ravichandran V, et al. The PDB data uniformity project. Nucleic Acids Res 2001;29(1):214-8. 